4. Полякова И.С. Системный анализ инфляционных процессов. «Ложная инфляционная спираль» / Актуальные проблемы науки и образования в условиях современных вызовов. / Сборник материалов II Международной научно-практической конференции (4 июля 2021 г., г. Москва) / Москва: ООО «Ирок» 2021- С.172-175.

5. Полякова И.С., Хисамов Ф.Г. Системный анализ инфляционных процессов и ценообразования в пусконаладочной деятельности / Международный научно-исследовательский журнал, №7, ч. 1, Екатеринбург, 2021, С.93-95.

\title{
Тихонов-Бугров Д.Е., Абросимов С.Н., Глазунов К.О. Проблемы обеспечения качества подготовки будущих инженеров в области компьютерной графики на начальной стадии обучения
}

Балтийский государственный технический университет «ВОЕНМЕХ» им. Д.Ф.Устинова (Россия, Санкт-Петербург)

doi: $10.18411 / 1 j-08-2021-32$

\section{Аннотация}

Рассматриваются особенности работы кафедр, осуществляющих графическую подготовку в технических университетах: ресурсы, выделенные на компьютерную графику; технологии обучения; критерии оценки качества обучения. Изложен опыт работы БГТУ «ВОЕНМЕХ» в данной сфере.

Ключевые слова: компьютерная графика, проектное обучение, технология, компетенции, качество.

\section{Abstract}

The features of the work of departments that carry out graphic training at technical universities are considered: resources allocated to computer graphics; learning technologies; criteria for assessing the quality of education. The experience of the BSTU "VOENMEKH" in this area is described.

Keywords: computer graphics, project training, technology, competencies, quality.

Формирование базовых навыков инженерной деятельности лежит в сфере ответственности кафедр, обеспечивающих графическую подготовку в технических университетах, которая осуществляется на первом и втором курсах. Обеспечение должного качества обучения в стеснённых, по временным ресурсам, условиям - весьма сложная задача. В формате Болонского процесса постоянно идут исследования в области обеспечения качества [1]. Только за 2006 - 2016 годы состоялось одиннадцать Европейских форумов по данной проблеме.

«Качество» - многогранное понятие. Как отмечается в [1] дефиниций качества высшего образования, как минимум, столько же, сколько имеется категорий заинтересованных сторон.

Среди большого многообразия вопросов обеспечения качества нас в данном случае будет интересовать компетентностный и результат-ориентированный подходы к оценке эффективности (качества) обучения. В этом случае главную роль играют мониторинг и аудит на основании описания ожидаемых результатов обучения с учётом временных ресурсов для обучения и академического консультирования.

Рассмотрим временные ресурсы, отведённые для изучения графики как таковой и компьютерной графики в частности. Заметим, что Болонское соглашение способствовало сведению к минимуму наличия специалитета в технических вузах. Особенно в тех, которые стремятся попасть во всевозможные зарубежные рейтинги. Понятно, что ресурсы для бакалавриата оказываются существенно скромнее, чем для специалитета. Данная проблема достаточно много освещается в ВАКовском журнале 
«Геометрия и графика». В статье [2], отмечается, что согласно ФГОС выпускник должен уметь решать «задачи проектных процедур» правильно, в соответствии с требованиями нормативных документов, оформлять проектную документацию, использовать компьютерные и информационные технологии, средства автоматизированного проектирования. Это основа пресловутого компетентностного подхода к обучению, в основе которого лежат требования неких работодателей, а не научное обоснование наличия необходимых знаний, умений, навыков, не отрицающих и владений.

Министр промышленности и торговли Д. Мантуров в своей знаменитой лекции [3] отметил необходимость широкой разносторонней подготовки современных инженеров. Однако не дал рекомендаций как это осуществлять в условиях компетентностного обучения.

Одним из следствий данной идеологии является убеждённость студентов в том, что есть нужные и ненужные предметы. Опрос студентов, проведённый авторами [4], показал, например, что более глубокое изучение компьютерной графики привлекательно только для $32 \%$ студентов. Это для будущих специалистов в области аэрокосмической промышленности!

При этом выясняется, что 35\% первокурсников графики в школе не изучали (даже в рамках дисциплины «Технология»), 96\% не изучали компьютерной графики. И вот, для работы с таким контингентом, в Пермском Национальном Исследовательском Политехническом Университете для подготовки специалистов для аэрокосмических отраслей отводится: в первом семестре 18 часов лекций и 22 часа практических занятий; на лабораторные занятия по компьютерной графике 8 часов. Остальное приходится на самостоятельную работу. Как в таких условиях организовать эффективный учебный процесс и оценить качество - большой вопрос.

По нашей информации в настоящее время приемлемая аудиторная нагрузка имеется в МГТУ им. Баумана, Санкт-Петербургском Горном университете, Военмехе. В этих университетах, благодаря поддержке руководителей - представителей отечественной инженерной школы, отводится три семестра на графическую подготовку. Причём, базой является начертательная геометрия, вытесняемая из учебного процесса во многих других университетах. Потеря теоретической базы приводит к потере самостоятельности кафедр [5] и прекращению их существования как самостоятельных единиц.

Что касается академического консультирования, то оно сводится к дополнительным занятиям, направленным на ликвидацию слабой базовой подготовки и традиционному консультированию цель которого - помощь в выполнении текущих заданий.

Не смотря на крайне бедный аудиторный ресурс, ряд университетов использует на начальной стадии обучения несколько графических пакетов, что только увеличивает нагрузку на этап самостоятельной работы. С учётом санкций, проблем, связанных с коронавирусом, наиболее рациональным, на наш взгляд, является использование отечественной разработки компании АСКОН «Компас».

В таких стеснённых условиях возрастает роль организации деятельности участников образовательного процесса. В [2] делается попытка увязать процесс обучения компьютерной графике с современными подходами к проектированию. По Джонсу [6] проектирование - мыслительная и практическая деятельность по определению общих целей и характера любой деятельности, лежащей в основе всей созидательной, преобразовательной практики и включённой в общую систему общественного производства. Из определения следует, что проект - практическая деятельность, т.е. процесс.

Однако авторы используют термин проектно-процессный подход [2], рассматривая процесс проектирования как некий чёрный ящик на выходе из которого, 
благодаря некоторым процессам получается готовая продукция. В чём заключается современный подход к проектированию и учебному процессу остаётся неясным. Разве что выстроенные в некую цепочку простые задания с применением графических пакетов. Главный недостаток данного подхода к образованию не сочинение и использование новых терминов, а отсутствие творческого подхода студента к проекту с использованием графического пакета как инструмента.

Если по примеру рассмотренной работы заняться терминологией, то следует учесть, что завершённость проекта определяется тремя фазами [7]:

- Проектирование, результатом которого является построение модели (системы) и плана её реализации.

- Технологическая фаза - реализация модели (системы).

- Рефлексивная фаза - оценка реализованной (системы) модели.

Технологии, наряду с проектами, программами, стали ведущей формой организации деятельности. А, значит, с современной позиции следует учитывать, что в массовых масштабах практикой востребован именно проектно-технологический тип организационной культуры.

Таким образом и строится учебный процесс в БГТУ «ВОЕНМЕХ» на этапе обучения инженерной графике с использованием компьютерной графики в качестве эффективного инструмента [8]. Проектное обучение на кафедре графики имеет давние традиции. Элементы творческой модификации изделий, связанных с будущей специальностью, появились в учебном процессе в восьмидесятые годы прошлого столетия. Естественно, что менялись и содержательная часть заданий и инструментарий. На начальной стадии изучения инженерной графики, когда идёт знакомство со стандартами ЕСКД, отраслевыми особенностями формирования электронных моделей и ассоциативных чертежей, проектные задачи сравнительно простые.

На заключительном этапе идёт процесс расслоения контингента по уровню способностей, уровню владения графическим пакетом, отношению к осваиваемому курсу. Своеобразным входным тестом являются два задания обязательные для всех. Это проект изделия, получаемого сваркой вместо литого варианта и построение модели и чертежа детали, при необходимости некоторой её модификации.

Студенты, справившиеся успешно с данным заданием в установленные сроки, допускаются к заключительному этапу. Это уже более сложный проект, суть которого в том, что студент анализирует представленную ему документацию, содержащую существенные недостатки в плане конструкторских решений. Далее он обсуждает с преподавателем пути преодоления этих недостатков и работает над моделью сборочной единицы и чертежами основных деталей с нанесением большого спектра дополнительной информации. Это касается шероховатостей поверхности, допусков и посадок, отклонения формы.

Студенты, не получившие права участвовать в заключительном этапе, оттачивают мастерство владения графическим пакетом в упражнениях на деталировку изделий, соответствующих их будущей специальности. Максимальная оценка в этом случае - «хорошо».

Качество работы студентов мы оцениваем по отмеченным выше трём фазам проектов: качество конструкторского решения и построения модели; реализация проекта средствами компьютерной графики; оценка студентом реализованной модели.

Труднее оценить качество собственной работы. Наиболее приемлемым вариантом является процент студентов, допущенных ко второму этапу, количество отличных оценок за второй этап. Однако, мы отчётливо понимаем, что из за расслоения по уровню базовой подготовки, способностям студентов в разных группах, мы не можем получить полностью объективные данные. Тем не менее, за последние 
несколько лет процент прошедших на второй этап вырос с 40\% до 60 (есть группы, где он составляет $80 \%$ ). Количество отличных оценок составляет $70-90 \%$.

Ещё одна важная проблема заключается в обеспечении непрерывности графической подготовки, падение уровня которой мы отчётливо видим при проведении нормоконтроля дипломных проектов и выпускных работ. Постепенно и профилирующие кафедры приходят к пониманию необходимости приложения усилий в данном направлении. В результате, кафедрой разработан курс для специалитета «Конструктивно-геометрическое моделирование технических объектов». Рассчитан такой курс на 11 семестр обучения. Лекций 14 часов, практики 28, самостоятельная работа 102 часа.

Цели освоения: ликвидация последствий разрыва процесса непрерывности графической подготовки студентов; развитие конструктивно-геометрического, логического и пространственного мышления при формировании геометрических моделей технических объектов; освоение приёмов формирования геометрических моделей в соответствии с современными требованиями к оформлению проектноконструкторской документации; знакомство с современным состоянием решения графических задач в САПР.

Широкая востребованность данного курса будет способствовать повышению качества подготовки инженеров в области инженерной и компьютерной графики.

1. Байденко В.И., Селезнёва Н.А. Обеспечение качества высшего образования: современный опыт (статья 2) // Высшее образование в России. 2017. № 11. С. 122-136.

2. Усатая Т.В., Дерябина Л.В., Решетникова Е.С. Современные подходы к проектированию изделий в процессе обучения студентов компьютерной графике // Геометрия и графика. 2019. Т.7. №1. С.7481.

3. Абросимов С.Н., Тихонов-Бугров Д.Е. Графическая подготовка в вузах в свете трендов Д.В. Мантурова // Труды международной научно-методической конференции «Современное образование: содержание, технологии, качество». СПб. 2017. Т.2. С. 87-89.

4. Шелякина Г.Г., Грошева Т.В. К вопросу об эффективности мониторинга качества графической подготовки студентов // Геометрия и графика. 2017. Т.5. №4. С.75-82.

5. Лепаров М.Н. Инженерная графика - TO BE, OR NOT TO BE. Материалы 3 международной научно-практической интернет-конференции «Проблемы качества графической подготовки» Пермь 2012.

6. Джонс Дж.К. Методы проектирования - М. Мир. 1986.

7. Селезнёва Н.А. Качество высшего образования как объект системного исследования - М.: Исследовательский центр проблем качества подготовки специалистов. 2004. - С.95.

8. Абросимов С.Н., Тихонов-Бугров Д.Е. Проектно-конструкторское обучение инженерной графике: вчера, сегодня, завтра // Геометрия и графика. - 2015. - Т.3. - №3. С.47-57.

\section{Фирсова С.А., Карпушкин А.С. \\ Разработка системы симуляции работы климатической камеры WK27/60-85 производства компании WEISS}

Мордовский государственный университет им. Н. П. Огарева doi: $10.18411 / \mathrm{j}-08-2021-33$

(Россия, Саранск)

\section{Аннотация}

Актуальность и цели. В настоящее время на высокотехнологичных производствах эффективным инструментом поддержания и повышения квалификации сотрудников является применение симуляторов работы оборудования, а также компьютерных тестирующих программ, разработанных с учетом индивидуальных особенностей предприятия. В данной работе рассматривается разработанная авторами программа симуляции работы климатической камеры WK27/60-85 производства 